\title{
Pendampingan Penyusunan LKPS dan LED Program Studi di Lingkungan FKIP sebagai Syarat Re-Akreditasi
}

\author{
Arifuddin', Arjudin², Jamaluddin³ ${ }^{3}$ A. A. Sukarso4, \\ Edy Kurniawansyah" ${ }^{5}$, Mohammad Archi Maulyda*6 \\ 1,2,3,4,5 Gugus Penjamin Mutu Fakulyas, FKIP, Universitas Mataram \\ *e-mail: archimaulyda@unram.ac.id ${ }^{1}$
}

\begin{abstract}
LKPS and LED mentoring activities are one of the duties and responsibilities of the Faculty Quality Assurance Unit (GPMF). The study programs that will participate in the mentoring activities are the Civics Education Study Program, the PGSD Study Program, and the Physics Education Study Program. The activity implementation method consists of 3 stages as follows: (1) Coordination meeting; (2) Implementation of Mentoring; and (3) Evaluation of Mentoring Activities. Assistance activities are carried out periodically within a period of 3 weeks. Each study program will be accompanied by 2 GPMF members. Based on the identified outcomes, the percentage of achievement of the outcomes is $66.67 \%$. This calculation is obtained from the number of completed outputs. The PPKn study program cannot complete the LKPS and LED, while the PGSD and Physics Education study programs can complete the LKPS and LED.
\end{abstract}

Keywords: Accreditation, Study Program Performance Evaluation, Quality Assurance

\begin{abstract}
Abstrak
Kegiatan pendampingan LKPS dan LED merupakan salah satu tugas dan tanggungjawab Unit Gugus Penjamin Mutu Fakultas (GPMF). Adapun prodi yang akan mengikuti kegiatan pendampingan adalah prodi PPKn, prodi PGSD, dan prodi Pendidikan Fisika. Metode pelakasanaan kegiatan terdiri dari 3 tahapan sebagai berikut: (1) Rapat koordinasi; (2) Pelaksanaan Pendampingan; dan (3) Evaluasi Kegiatan Pendampingan. Kegiatan pendampingan dilaksanakan secara berkala dalam kurun waktu 3 minggu. Setiap program studi akan didampingi oleh 2 orang anggota GPMF. Berdasarkan hasil luaran teridentifikasi, persentase ketercapaian luaran adalah 66,67 \%. Perhitungan ini didapat dari jumlah luaran yang terselesaikan. Prodi PPKn tidak dapat menyelesaikan LKPS dan LED, sedangkan prodi PGSD dan Pendidikan Fisika dapat menyelesaikan LKPS dan LED.
\end{abstract}

Kata kunci: Akreditasi, Evaluasi Kinerja Program Studi, Penjaminan Mutu

\section{PENDAHULUAN}

Laporan evaluasi diri merupakan dokumen evaluasi suatu institusi yang mampu memperlihatan ketercapaian dan ketidaktercapaian suatu kriteria yang sudah ditetapkan, sehingga berdasarkan hal itu maka bisa dilakukann usaha-usaha perbaikan, demikian juga dengan insitusi pendidikan tinggi (Sugilar et al., 2019);(Widiastuti et al., 2019);(Wahyono et al., 2018). Agar menghasilkan lulusan yang memiliki kompetensi yang diinginkan dunia kerja, perguruan tinggi dituntut untuk selalu mampu menjaga dan meningkatkan kualitas penyelenggaraan layanan pendidikannya. Salah satu siklus yang harus dijalani untuk melaksanakan hal itu adalah menempuh proses akreditasi program studi oleh BAN-PT (Hasballah, 2021). Banyak pihak menganggap bahwa proses akreditasi adalah kegiatan administrasi yang sifatnya rutinitas dalam periode waktu tertentu, padahal sesungguhnya jauh lebih dalam lagi sebagai upaya melihat ke dalam, merefleksikan diri, melakukan kajian sudah ada dimana kita saat ini, dan mau kemana selanjutnya perahu program studi akan dibawa (Sapurta, 2020);(Putri, 2020).

Laporan Evaluasi Diri program studi PGSD, PPKN \& Pendidikan Fisika FKIP UNRAM disusun sebagai upaya komprehensif dan berkelanjutan untuk memperoleh gambaran kinerja dan keadaan dirinya melalui pengkajian dan analisis mendalam mengenai kekuatan, kelemahan, peluang, dan ancaman. Berdasarkan analisis tersebut diharapkan akan muncul strategi pengembangan yang dapat digunakan sebagai dasar perencanaan lebih lanjut (Kusuma et al., 2018). Proses evaluasi diri dilakukan secara internal oleh tim penyusun LKPS \& LED yang ditunjuk oleh pimpinan FKIP UNRAM. Tim ini bekerja berdasarkan hasil pengumpulan data yang dilakukan 
oleh tim task force bekerjasama dengan dosen, tata usaha, mahasiswa dan stake holder's yang analisisnya disajikan dalam laporan ini. Kegiatan bertujuan untuk melengkapi dokomen LKPS dan LED pada prodi PGSD, PPKN dan Pendidikan Fisika sebagai persiapan re-akreditasi.

\section{METODE} antara lain:

Kegiatan pendampingan penyusunan LKPS dan LED dilakukan dalam beberapa tahapan
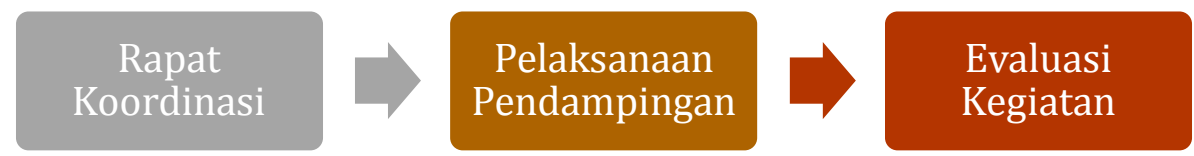

Gambar 1. Tahapan kegiatan pendampingan LKPS dan LED

Kegiatan pendampingan dilaksanakan secara berkala pada 3 program studi yang akan habis masa Akreditasinya tanggal 13 April 2021. Ketiga program studi yang dimaksud adalah Prodi PPKn, Prodi PGSD, dan Prodi Pendidikan Fisika. Kegiatan pendampingan dilaksanakan secara bersamaan di ruangan yang berbeda. Tim Gugus Penjamin Mutu Fakultas (GPMF), membagi diri kedalam 3 tim pendamping dimana setiap tim berisi 2 orang anggota GPMF. Proses pendampingan dilaksanakan secara offline (tatap muka) dan dilakukan evaluasi setiap selesai pendampingan.

\section{HASIL DAN PEMBAHASAN}

Kegiatan pendampingan pengisian LKPS dan penyusunan LED pada masing-masing prodi dilaksanakan dalam beberapa tahapan. Adapun perincian setiap tahap sebagai berikut.

\subsection{Mengadakan rapat koordinasi}

Kegiatan rapat koordinasi ini dilaksanakan pada hari Kamis, 4 Maret 2020, pukul 10.00 WITA. Kegiatan rapat dilaksanakan di ruang Workshop FKIP, Gedung A lantai 2. Kegiatan rapat diikuti oleh semua tim GPMF yang terlibat dalam kegiatan pendampingan (Daftar hadir terlampir). Berdasarkan hasil rapat koordinasi ini, tim membagi diri dalam tim pendamping pada masing-masing prodi seperti berikut:

a. Prodi Pendidikan Fisika (Prof. Dr. Ariffudin, M. Pd. \& Dr. Jamaluddin, M. Pd.)

b. Prodi Pendidikan Guru Sekolah Dasar (Dr. A. A. Sukarso, M. Si. \& Mohammad Archi Maulyda, S. Pd., M. Pd.)

c. Prodi Pendidikan Pancasila dan Kewarganegaan (Dr. Arjuddin, M. Si. \& Edy Kurniawansyah)

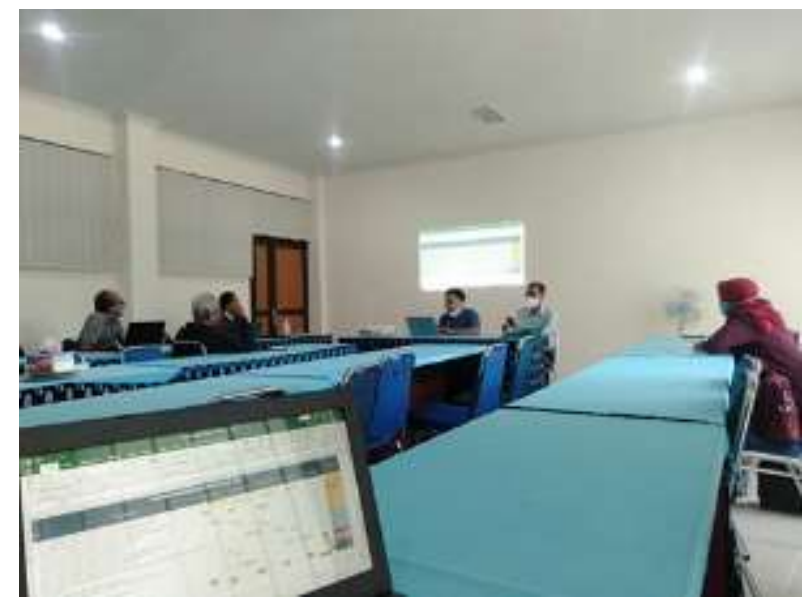

Gambar 2. Rapat Koordinasi Kegiatan Pendampingan GPMF 
Selain itu, hasil rapat juga menhasilkan timeline kegiatan pendampingan yang akan dilaksanakan. Kegiatan akan dilaksanakan selama 2 minggu yakni per tanggal 8-19 Maret 2021.

\subsection{Melaksanakan kegiatan pendampingan}

Kegiatan pendampingan dilakukan menyesuaikan dengan jadwal masing-masing tim akreditasi di Prodi. Dalam hal ini, koordinasi akan dilakukan antara pendamping dengan Kaprodi yang program studinya akan re-akreditasi. Kegiatan pendampingan pertama dilaksanakan pada hari Senin, 8 Maret 2021 di program studi PGSD. Sedangkan pada prodi Pendidikan Fisika, pendampingan pertama kali dilaksanakan pada hari Rabu, 10 Maret 2021. Untuk prodi PKN, pendampingan pertama dilaksanakan pada hari Kamis, 11 Maret 2021.

Berdasarkan hasil kegiatan pendampingan di prodi PGSD, tim pendamping menyimpulkan masih banyak kekurangan pada pengisian LKPS, sehingga masing-masing standar masih kesulitan merumuskan LED. Masukan untuk tim akreditasi PGSD adalah merubah sistem kerja menjadi tim PGSD, bukan bekerja pada masing-masing standar. Bekerja pada masingmasing standar ini menyebabkan kesulitan pada perumusan LED yang saling berkaitan.

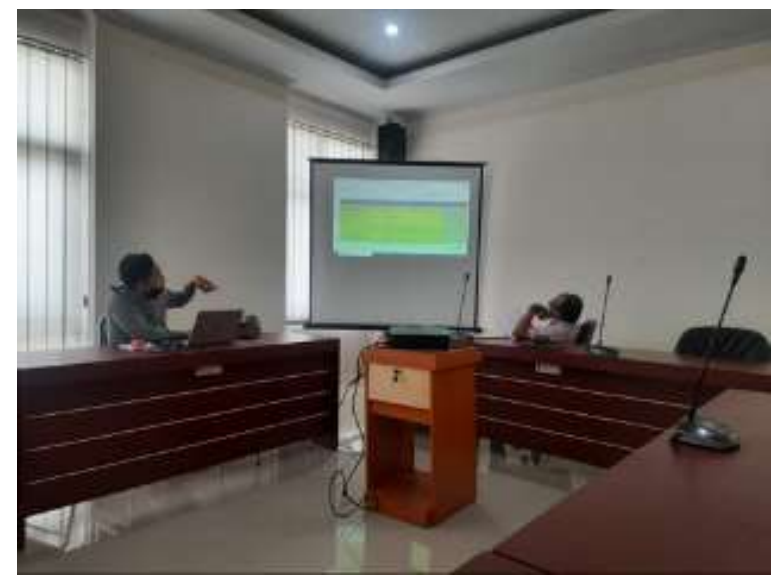

Gambar 3. Pendampingan Penyusunan LED dan LKPS Prodi PGSD

Untuk prodi Pendidikan Fisika, proses pengisian LKPS sudah cukup lengkap. Hal ini mempermudah proses perumusan LED, selain itu tim akreditasi Pendidikan Fisika sudah bekerja dalam 1 tim. Sehingga data-data pada masing-masing standar sudah singkron dan mudah untuk di deskripsikan pada LED.

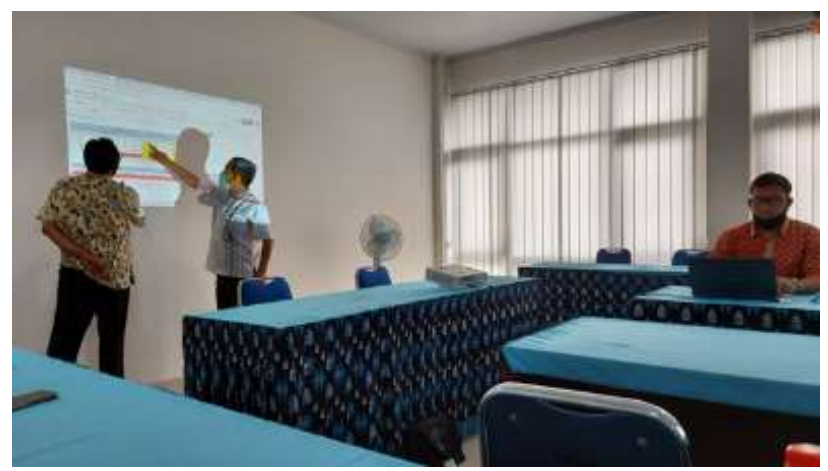

Gambar 4. Pendampingan Penyusunan LED dan LKPS Prodi Pend. Fisika 


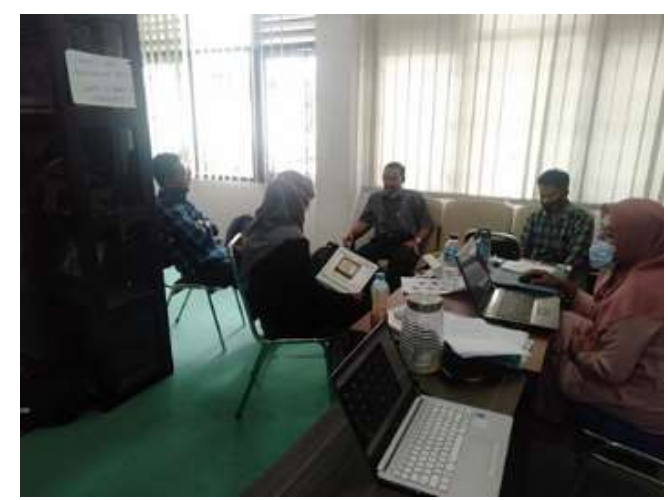

Gambar 5. Pendampingan Penyusunan LED dan LKPS Prodi PKN

Untuk Prodi Pendidikan Pancasila dan Kewarganegaraan, masalah utama ketika dilakukan pendampingan adalah keterbatasan data yang dimiliki. Hal ini dikarenakan persiapan Prodi masih kurang maksimal. Koordinasi antar tim juga masih belum terjalin secara sistematis, sehingga fokus utama pendampingan adalah pada persiapan data dan pengisian LKPS. Pendampingan belum sampai pada penyusunan LED.

Kegiatan evaluasi LKPS dan LED prodi-prodi yang diproyeksikan akan re-akreditasi dilaksanakan sebanyak 2 kali. Evaluasi kegiatan pertama dilaksanakan secara internal oleh Pimpinan (Dekan dan Wakil Dekan). Kegiatan ini dilaksanakan pada hari Rabu, 17 Maret 2020 di Ruang Sidang Dekan II FKIP Unram. Kegiatan ini dihadiri oleh Prof. Dr. H. A Wahab Jufri, M.Sc. (Dekan FKIP), Dr. Gunawan, M. Pd. (Wakil Dekan I), Dr. Sukardi, M. Pd. (Wakil Dekan II), dan Dr. Gito Hadiprayitno, M. Si. (Wakil Dekan III) serta Ketua Gugus Penjamin Mutu Fakultas (GPMF) Prof. Dr. Arifuddin, M.Pd. Selain itu, kegiatan ini juga tentu dihadiri oleh ketiga tim akreditasi yakni dari Prodi PKN, PGSD dan Pend. Fisika.

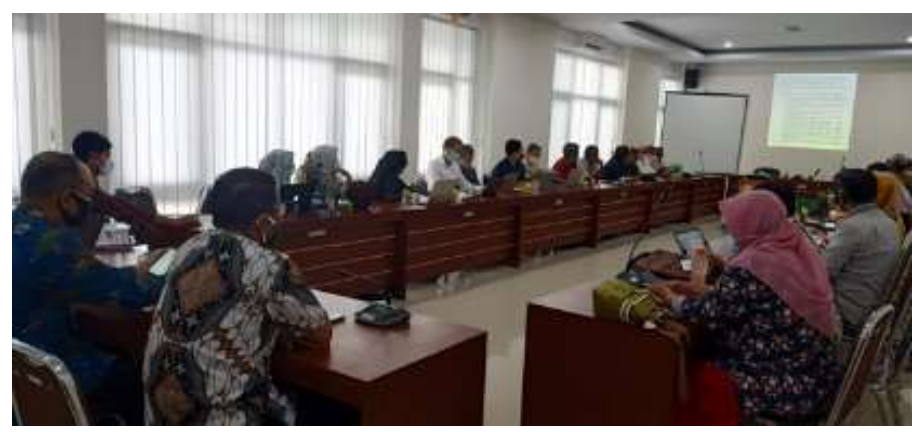

Gambar 6. Kegiatan Evaluasi oleh Pimpinan FKIP

Pada kegiatan ini, program studi PGSD dan Pend. Fisika mempresentasikan hasil penyusunan LKPS dan LED yang telah dikerjakan. Untuk prodi PKN, setelah dilaksanakan pendampingan dan evaluasi mandiri di lingkup prodi, hasil analisis menunjukkan bahwa masih banyak data pada LKPS yang belum terisi. Hal ini menyebabkan LED prodi PKN tidak dapat disusun. Berdasarkan perhitungan tim GPMF juga menunjukkan bahwa batas tanggal pengajuan re-akreditasi prodi PKN telah berakhir. Berdasarkan pada dua hal tersebut, GPMF merekomendasikan prodi PKN untuk memperpanjang masa akreditasi dengan catatan, perisapan akreditasi tetap berjalan. Sedangkan untuk prodi PGSD, hasil evaluasi menunjukkan adanya masalah tidak singkronya data jumlah mahasiswa yang dimiliki Fakultas, dengan data yang ada di PD-Dikti. Untuk penyusunan LED, sudah hampir lengkap tinggal menunggu nomor surat yang belum dimasukkan. Poin yang belum termuat pada LED prodi PGSD adalah analisis ketercapaian, analisis SWOT, pengembangan strategi, dan keberlanjutan program. Kemudian untuk prodi Pend. Fisika, baik LKPS dan LED yang telah disusun sudah cukup lengkap. Hampir sama dengan prodi PGSD, masalah utama yang ditemui adalah jumlah mahasiswa aktif yang tidak sama antara data di Fakultas dengan yang ada di PD-Dikti. 
Kegiatan evaluasi selanjutnya dilaksanakan oleh Lembaga Penjaminan Mutu dan Pengembangan Pembelajaran (LPMPP). Kegiatan ini dilaksankaan pada hari Kamis, 25 Maret 2021 di Ruang Sidang II FKIP Unram. Kegiatan ini dihadiri oleh Bapak Dr. Ir. Lestari Ujianto, M.Sc. dan Dr. Sitti Latifah, S.Hut., M.Sc.F., sebagai perwakilah dari pihak LPMPP. Kegiatan ini juga dihadiri pimpinan FKIP, para ketua jurusan dan ketua program studi di FKIP, serta tim akreditasi PGSD dan Pend. Fisika.
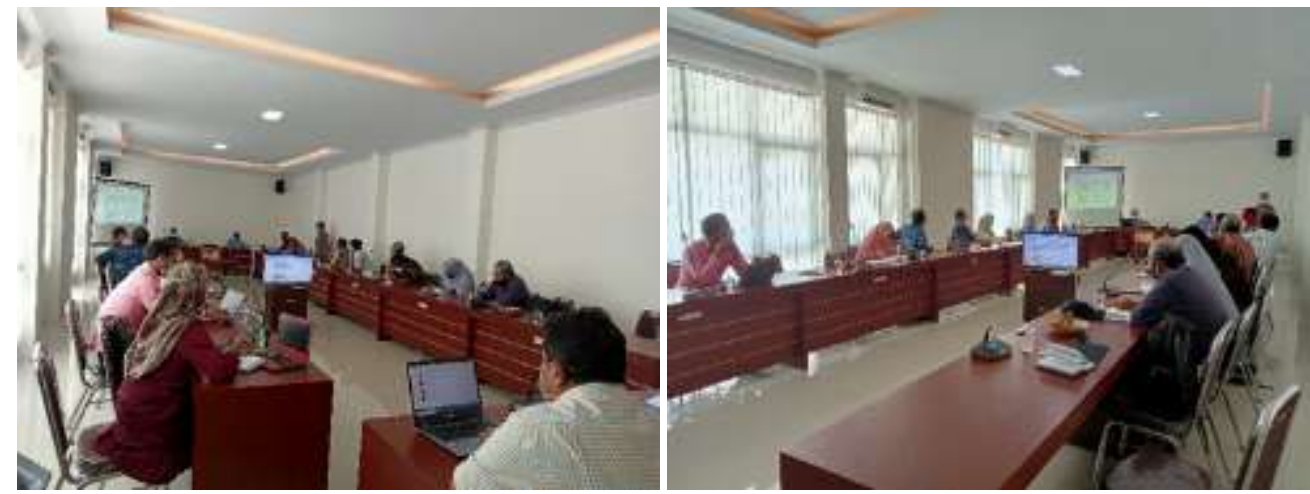

Gambar 7. Kegiatan Evaluasi Penyusunan LKPS dan LED oleh LPMPP

Berdasarkan hasil evaluasi, prodi PGSD masih jauh dari nilai minimal untuk mendapatkan predikat unggul. Untuk mendapat nilai unggul, skor LKPS dan LED prodi minimal adalah 3,61. Sedangkan nilai yang didapat oleh prodi PGSD adalah 3,26. Selain nilai yang belum terpenuhi, prodi PGSD juga masih belum dapat memenuhi syarat khusus untuk dapat mendapatkan predikan prodi yang Unggul. Syarat yang belum terpenuhi adalah kualifikasi dosen bergelar Doktor (S3) dan kualifikasi jabatan fungsional Lektor kepala yang masih sedikit.

Untuk prodi Pend. Fisika, nilai yang didaptkan adalah 3,53, artinya prodi Pend. Fisika berpeluang besar untuk dapat mendapatkan predikat prodi yang Unggul. Meskipun demikian prodi Pend. Fisika juga masih terganjal pada syarat khusus, yakni kekurangan satu orang dosen yang bergelar Doktor. Diluar itu, data-data yang dimiliki prodi Pend. Fisika telah lengkap dan siap untuk mengajukan re-akreditasi. Namun, perlu dipertimbangkan juga untuk perpanjangan selama satu tahun sambal menunggu dosen-dosen yang sedang menempuh S3 agar syarat khusus untuk menjadi unggul dapat terpenuhi.

Ketercapaian luaran kegiatan dapat dilihat dari ketersediaan dokumen LKPS dan LED pada masing-masing prodi. Untuk prodi PKN dokumen LKPS dan LED tidak terisi dengan lengkap karena masih perlu adanya pengumpulan data yang lebih komperhensif. Sedangkan untuk LKPS dan LED prodi PGSD dan Pend. Fisika sudah lengkap. Dengan demikian persentase ketercapaian luaran kegiatan dapat dihitung berdasarkan rumus berikut (Rohmah et al., 2016):

$$
\begin{aligned}
& \leftrightarrow \text { Ketercapaian Luaran }=\frac{\text { Jumlah luaran yang tercapai }}{\text { Jumlah luaran yang diharapkan }} \times 100 \\
& \leftrightarrow \text { Ketercapaian Luaran }=\frac{4}{6} \times 100 \\
& \leftrightarrow \text { Ketercapaian Luaran }=66,67 \%
\end{aligned}
$$

Dalam pelaksanaan kegiatan pendampingan, tim GPMF menemui beberapa kendala seperti berikut ini:

1. Berbenturanya jadwal pendampingan tim akreditasi dengan jadwal kuliah para dosen. Hal ini menyebabkan tidak banyak dosen yang bisa terlibat dalam proses pendampingan.

2. Masih banyak data yang belum tersedia di prodi yang akan diakreditai, sehingga dalam melengkapi LKPS diperlukan waktu yang cukup lama.

3. Mekanisme penyelesaian LED masih berbasis masing-masing standar, sehingga data-data masih banyak yang tidak tersingkron. 
4. Perubahan panduan akreditasi BAN-PT dari yang awalnya berisi 7 standar, menjadi 9 standar, menyebabkan dosen kesulitan mengimplementasikan pengalaman akreditasi sebelumnya untuk menyelesaikan LKPS dan LED pada akreditasi tahun 2021

\section{KESIMPULAN}

Berdasarkan hasil kegiatan pendampingan yang dilaksanakan, dapat disimpulkan beberapa hal sebagai berikut:

1. Prodi PPKn tidak dapat menyelesaikan LKPS dan LED karena terlalu banyak data yang belum tersedia.

2. Prodi PGSD dan Pendidikan Fisika dapat menyelesaikan LKPS dan LED dengan baik.

3. Berdasarkan hasil evaluasi kegiatan, ketercapaian luaran kegiatan adalah $66,67 \%$.

4. Tindak lanjut kegiatan adalah melakukan simulasi re-akreditasi yang dipandu oleh pihak Lembaga Penjaminan Mutu dan Pengembangan Pendidikan (LPMPP) Universtas Mataram

\section{DAFTAR PUSTAKA}

Hasballah, M. A. (2021). The influence of knowledge management on lecturer performance through job satisfaction. Management Science Letters, 12(8), 959-964. https://doi.org/10.5267/j.msl.2020.10.001

Kusuma, A. H. P., Rina, R., \& Syam, A. H. (2018). The Main Role of Locus of Control and Professional Ethics on Lecturer's Performance (Indonesian Lecturer Empirical Study). International Review of Management and Marketing, 8(5), 9-17.

Putri, I. A. J. (2020). Analysis of the influence of compensation organizational culture, and work discipline on the performance of lecturer Surabaya Shipping Polytechnic. Research, Society and Development, 9(5), e05952746. https://doi.org/10.33448/rsd-v9i5.2746

Rohmah, N., Huda, M., \& Kusmintardjo. (2016). Strategi Peningkatan Kemampuan Dosen dalam Penulisan Karya Ilmiah ( Studi Multi Kasus pada UNISDA dan STAIDRA di Kabupaten Lamongan). Jurnal Pendidikan: Teori, Penelitian, Dan Pengembangan, 1(7), 1312-1322.

Sapurta, A. (2020). Pemanfaatan Science and Technology Index (SINTA) untuk Publikasi Karya Ilmiah dan Pencarian Jurnal Nasional Terakreditas. Media Pustakawan, 27(1), 56-68.

Sugilar, H., Priatna, T., \& Darmalaksana, W. (2019). Strategi Perguruan Tinggi Dalam Meningkatkan Publikasi Hasil Penelitian. Al-Fikrah: Jurnal Manajemen Pendidikan, 7(1), 45. https://doi.org/10.31958/jaf.v7i1.847

Wahyono, W., Prihandono, D., \& Wijayanto, A. (2018). Behavioural Assessment Perspective on Reward System Management and Performance: An Empirical Finding on Indonesian $\begin{array}{llll}\text { Lecturer. Jurnal Dinamika } & \text { Manajemen, }\end{array}$ https://doi.org/10.15294/jdm.v9i1.14654

Widiastuti, R., Haryono, B. S., \& Said, A. (2019). Influence of System Quality, Information Quality, Service Quality on User Acceptance and Satisfaction and Its Impact on Net Benefits (Study of Information System Users Lecturer Performance Load (BKD) in Malang State University). HOLISTICA - Journal of Business and Public Administration, 10(3), 111-132. https://doi.org/10.2478/hjbpa-2019-0032 